\title{
Effect analysis on heavy tuned mass damper system used in urban transportation
}

\author{
L. $\mathrm{Li}^{1}$, C. Geng ${ }^{1} \& \mathrm{Q} . \mathrm{Yu}^{2}$ \\ ${ }^{1}$ Railway and Urban Mass Transit Research Institute, \\ Tongji University, China \\ ${ }^{2}$ Shanghai Tunnel Engineering and \\ Rail Transit Design and Research Institute, China
}

\begin{abstract}
A tuned mass damper (TMD) is an effective structure. When the mass of TMD is bigger, the effect to vibration reduction is better. In order to study the heavy tuned mass damper (HTMD) vibration reduction effect, three methods have been covered in this paper. The first is to analyze its natural frequencies and mode shapes. By comparing HTMD with common track, the performance of moderate and high frequency vibration attenuation has been verified. The second is the finite element study of wheel load drop on the track structure to simulate the real wheel impact. The stability and performance of damping property under impact load has been confirmed. Meanwhile, through dynamic load, parameter responses of tracks have been obtained. Comparing the track which uses HTMD with the common one, it can be concluded that the HTMD system fixed on the rail is effective.
\end{abstract}

Keywords: heavy tuned mass damper, natural frequency, wheel load drop, dynamic response.

\section{Introduction}

Rail transit in China has been developing very rapidly in the past dozens of years. Because most urban rail transits pass through downtown, the vibration and noise has a great impact on the environment. The vibration and noise directly affects people's living conditions and health, especially to those who live and work along the lines. A lot of research work has been undertaken on rail transit 
vibration noise control worldwide. And successful experience and useful results have been gained.

Vibration and noise control is one of the hot spots of the present research [14]. According to whether energy input is needed from the outside world or not, it is divided into two methods, these are active control and passive control. Theoretically, active control is better than passive control. However, owing to the theory and engineering practice conditions, most mature technology is passive control at present in engineering applications. Tuned mass dampers are one of the most typical applications. Tuned mass dampers have the role of stabilization to the fierce spot caused by harmonic vibration. It can use components to suppress the vibration. Even in the most difficult conditions it also can have the role of vibration reduction.

\section{Tuned mass dampers and vibration principle}

A TMD is a vibration system composed of a spring, damper and mass, also known as an active mass damper or harmonic shock absorber, which is a second vibration system installed in the main vibration system. Through the proper regulation subsystem of the vibration characteristics, the vibration energy of the primary system can transfer to the subsystem, and consume in one of the damping links [5].

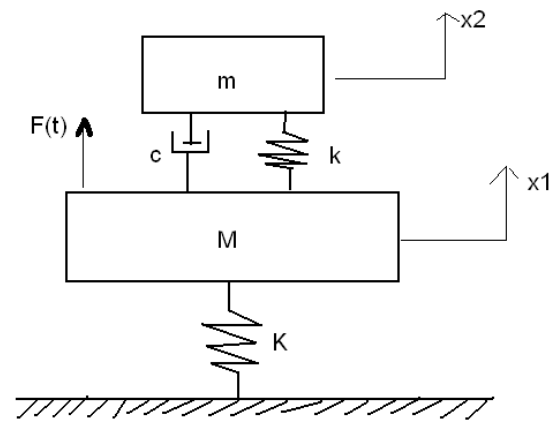

Figure 1: Two-degree freedom model of TMD.

Figure 1 is a common two-degree freedom vibration model for TMD. Among them, as the object of vibration control the main system is composed of a mass $M$ and spring $K$. The natural frequency is $\omega_{1}$. In order to simplify the model, main system damping is not considered. TMD is built by a mass $m$, spring $k$ and damping $c$ being an additional system whose natural frequency is $\omega_{n}$. The system of the motion equation is

$$
\begin{gathered}
M \ddot{x}_{1}+c\left(\dot{x}_{1}-\dot{x}_{2}\right)+K x_{1}+k\left(x_{1}-x_{2}\right)=F \\
m \ddot{x}_{2}+c\left(\dot{x}_{2}-\dot{x}_{1}\right)+k\left(x_{1}-x_{2}\right)=0
\end{gathered}
$$


Considering the simple harmonic $\operatorname{load} F(t)=F_{0} e^{j \omega t}$, the response can be expressed as

$$
x_{1}=X_{1} e^{j \omega t}, x_{2}=X_{2} e^{j \omega t}
$$

The amplitude of main vibration system is deduced as

$$
\left|X_{1}\right|=\sqrt{\frac{\left(k-m \omega^{2}\right)^{2}+(\omega c)^{2}}{\left[()()-m k \omega^{2}\right]^{2}+\left[K-(M+m) \omega^{2}\right]^{2}(\omega c)^{2}} F_{0}}
$$

Introducing the following items:

Mass ratio $\mu=\frac{m}{M}$; damping ratio $\varsigma=\frac{c}{2 \sqrt{m k}} ;$ static deformation $X_{s t}=\frac{F_{0}}{K}$; forced vibration frequency ratio $\lambda=\frac{\omega}{\Omega_{n}}$; natural frequency ratio $\gamma=\frac{\omega_{n}}{\Omega_{n}}$

Then the result will be as follows:

$$
\frac{\left|X_{1}\right|}{X_{s t}}=\sqrt{\frac{\left(\gamma^{2}-\lambda^{2}\right)^{2}+(2 \lambda \gamma \varsigma)^{2}}{\left[\left(1-\lambda^{2}\right)\left(\gamma^{2}-\lambda^{2}\right)-\mu \gamma^{2} \lambda^{2}\right]^{2}+\left[1-(1+\mu) \lambda^{2}\right]^{2}(2 \lambda \gamma \varsigma)^{2}}}
$$

Eqn (4) is the vibration rate for amplitude of the main system using TMD. If the mass ratio and natural frequency are given, amplitude can be calculated. If we make $\mu$ and $\gamma$ be a certain value separately, according to the different damping ratio, the vibration ratio of amplitude curves can be plotted. If damping is infinite, it is equivalent that TMD is fixed on the main vibration system. It becomes a single freedom without damping, and resonant amplitude is infinite; when damping is 0 , the TMD makes the resonance frequency divide into two new resonance frequencies, whose amplitude is still infinite. Then between 0 and infinite, there muse be a best damping value. There are two crossing points such as $\mathrm{P}$ and $\mathrm{Q}$ in the amplitude curves. The position of these two points is not affected by damping. The amplitude of the main system should be the minimum. If we make the two points be at the same height, and let them be the peak of the curves, the TMD will be the best system that we can hope for.

When $\varsigma=0$ and $\varsigma=\infty$, the results can be

$$
\begin{gathered}
\left|\frac{X_{1}}{X_{s t}}\right|_{\varsigma=0}=\left|\frac{\gamma^{2}-\lambda^{2}}{\left(1-\lambda^{2}\right)\left(\gamma^{2}-\lambda^{2}\right)-\mu \gamma^{2} \lambda^{2}}\right| \\
\left|\frac{X_{1}}{X_{s t}}\right|_{\varsigma=\infty}=\left|\frac{1}{1-(1+\mu) \lambda^{2}}\right|
\end{gathered}
$$


The points $\mathrm{P}$ and $\mathrm{Q}$ are located at the cross point of the vibration ratio of the amplitude curves when $\varsigma=0$ and $\varsigma=\infty$. Their positions are not affected by damping, while they are affected by the ratio of natural frequency. When the mass of TMD is bigger, the effect to vibration reduction is better.

Therefore, in this paper the object is to focus on the HTMD system which is fixed on the rail (Fig. 2).

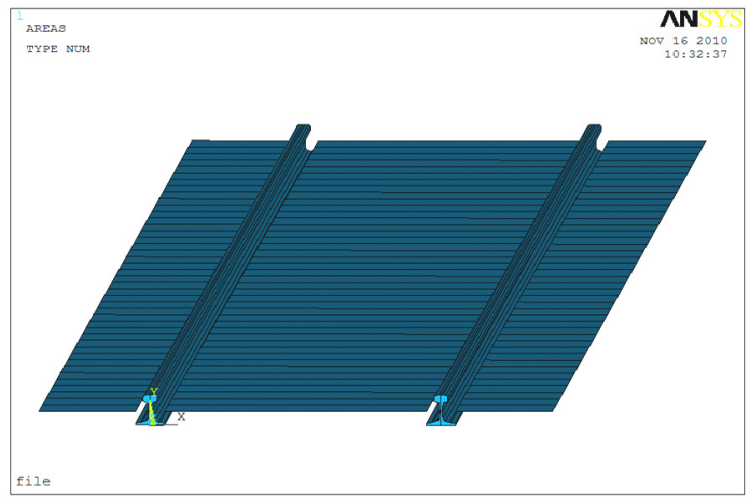

Figure 2: $\quad$ Heavy tuned mass damper.

\section{Modal analysis}

According to the above theoretical analysis, we can analyze the natural frequencies of the common track and the track with HTMD on the rail. The main parameters are shown in Table 1.

Table 1: $\quad$ Common track and track with TMD on the rail.

\begin{tabular}{|c|c|c|}
\hline \multicolumn{2}{|r|}{ Parameters } & Reference value \\
\hline \multirow[t]{5}{*}{ rail } & $\operatorname{size}(\mathrm{kg} / \mathrm{m})$ & 60 \\
\hline & cross-section area $\left(\mathrm{cm}^{2}\right)$ & 77.45 \\
\hline & elastic modulus ( $G P a$ ) & 210 \\
\hline & passion ratio & 0.3 \\
\hline & calculated length $(\mathrm{m})$ & 25 \\
\hline \multirow[t]{2}{*}{ fastener } & stiffness $(\mathrm{kN} / \mathrm{mm})$ & $6,25,50$ \\
\hline & damping $(N \cdot s / m)$ & $7.5 e^{4}$ \\
\hline HTMD & \multicolumn{2}{|c|}{$\begin{array}{l}\text { length between two rails: } 1.35 \mathrm{~m} \text {; } \\
\text { length outside of rail: } 0.5 \mathrm{~m} \text {; } \\
\text { thickness: } 120 \mathrm{~mm}\end{array}$} \\
\hline spring & TMD and rail $(\mathrm{kN} / \mathrm{m}$ & $200 e^{6}$ \\
\hline
\end{tabular}


Table 2: $\quad$ Natural frequencies of common track and the one with HTMD.

\begin{tabular}{|c|c|c|c|c|c|c|c|}
\hline & $\begin{array}{c}\text { Nodal } \\
\text { stiffness } \\
(\mathrm{kN} / \mathrm{mm})\end{array}$ & $\begin{array}{c}\text { 1st } \\
(\mathrm{Hz})\end{array}$ & $\begin{array}{c}\text { 2nd } \\
(\mathrm{Hz})\end{array}$ & $\begin{array}{c}\text { 3rd } \\
(\mathrm{Hz})\end{array}$ & $\begin{array}{c}\text { 4th } \\
(\mathrm{Hz})\end{array}$ & $\begin{array}{c}\text { 5th } \\
(\mathrm{Hz})\end{array}$ & $\begin{array}{c}\text { 6th } \\
(\mathrm{Hz})\end{array}$ \\
\hline \multirow{4}{*}{ common } & 6 & 65.028 & 65.335 & 66.372 & 68.62 & 72.398 & 78.214 \\
\cline { 2 - 8 } & 25 & 132.5 & 132.67 & 133.25 & 134.61 & 137.19 & 141.39 \\
\hline \multirow{3}{*}{ HTMD } & 50 & 187.02 & 187.15 & 187.58 & 188.6 & 190.55 & 193.83 \\
\cline { 2 - 8 } & 6 & 18.821 & 22.071 & 26.657 & 32.049 & 33.069 & 37.943 \\
\cline { 2 - 8 } & 25 & 25.609 & 28.028 & 31.681 & 36.231 & 38.116 & 40.228 \\
\hline
\end{tabular}

From the data in Table 3, it can be seen that the natural frequencies of the rail with HTMD is smaller than those of common track, which explains that tuned mass has a certain effect on vibration control.

Table 3: $\quad$ Vertical displacement of rail $(\mathrm{mm})$.

\begin{tabular}{|c|c|c|c|}
\hline \multirow{2}{*}{} & \multicolumn{3}{|c|}{ fastener stiffness $(\mathrm{kN} / \mathrm{mm})$} \\
\cline { 2 - 4 } & 6 & 25 & 50 \\
\hline common track & 1.245 & 1.06 & 0.899 \\
\hline HTMD & 0.644 & 0.623 & 0.599 \\
\hline
\end{tabular}

The natural frequencies of the track structure vary with the stiffness of the fasteners. Track vibration frequency will increase as the stiffness of fasteners increase. Therefore, in order to achieve a better vibration reduction effect, a tuned mass damper system should match the stiffness of the fasteners.

Table 4: $\quad$ Fastener force $(k N)$.

\begin{tabular}{|c|c|c|c|}
\hline \multirow{2}{*}{} & \multicolumn{3}{|c|}{ Fastener stiffness $(\mathrm{kN} / \mathrm{mm})$} \\
\cline { 2 - 4 } & 6 & 25 & 50 \\
\hline common track & 42.889 & 60.503 & 81.476 \\
\hline HTMD & 21.521 & 32.62 & 50.018 \\
\hline
\end{tabular}

The first-order frequency of the track with HTMD is about $20 \mathrm{~Hz}$, which is close to that of a light floating slab track (FST). This structure (HTMD) makes full use of existing railway structure space, which can be used in line transformation.

\section{Wheel-set drop simulation}

As a train runs through the track with irregularities on the rail surface, the wheel tread may separate with the top of the rail. Because the springs under the bogie 
are in a compression state, when the wheel does not contact with the rail, the compressed spring will push the wheel bounce to the rail, which causes the wheel/rail impact. Based on the principle, we use the wheel-set drop method to simulate. Wheel-set fall down freely from a certain height will make wheel-set impact vertically to rail, which makes the track structure vibrate. Through the attenuation of rail impact amplitude and all the parts of the track vibration, we determine the effect of track structure stiffness and damping parameters on vibration attenuation characteristics [6].

The parameters of rail and track are in Table 1 . The wheel parameters are as follows:

The wheel model: PLANE42 elements, grid partition using mapping way, quadrilateral grid shape. Take wheel thickness of $0.0627 \mathrm{~m}, 1.25 \mathrm{~m}$ in diameter.

The wheel-set fall height is taken at $20 \mathrm{~mm}$. This height can simulate the wheels' bounces on the rail irregularities state.

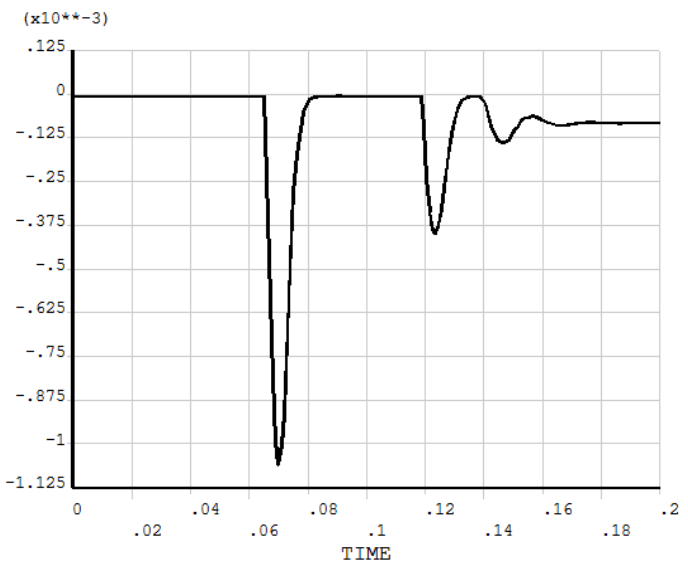

Figure 3: Displacement of rail (common track).

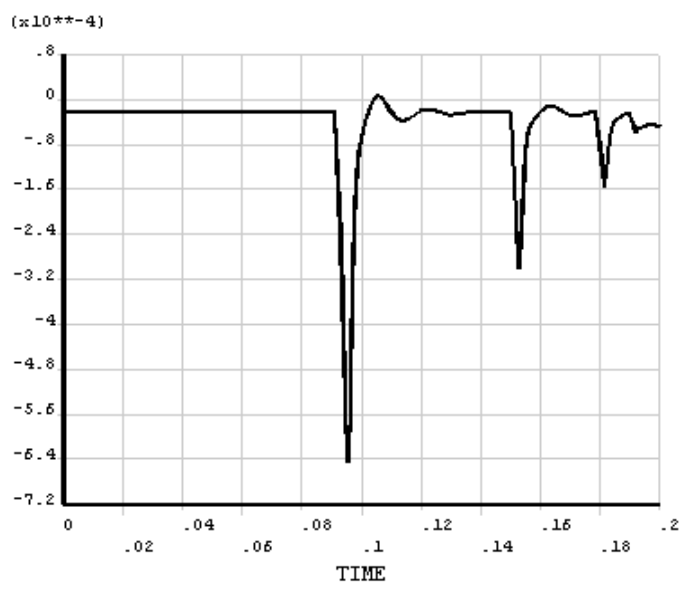

Figure 4: Displacement of rail $(\mathrm{HTMD}, \mathrm{k}=6 \mathrm{kN} / \mathrm{mm})$. 


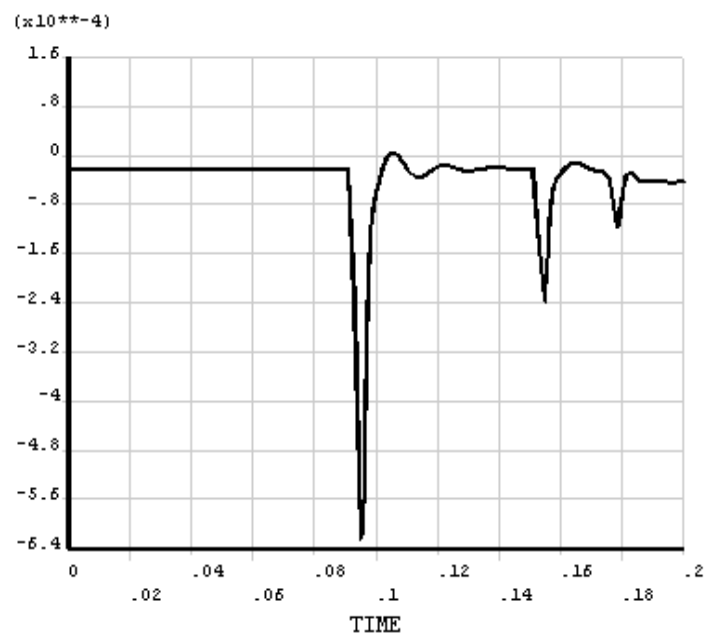

Figure 5: Displacement of rail (HTMD, $\mathrm{k}=25 \mathrm{kN} / \mathrm{mm})$.

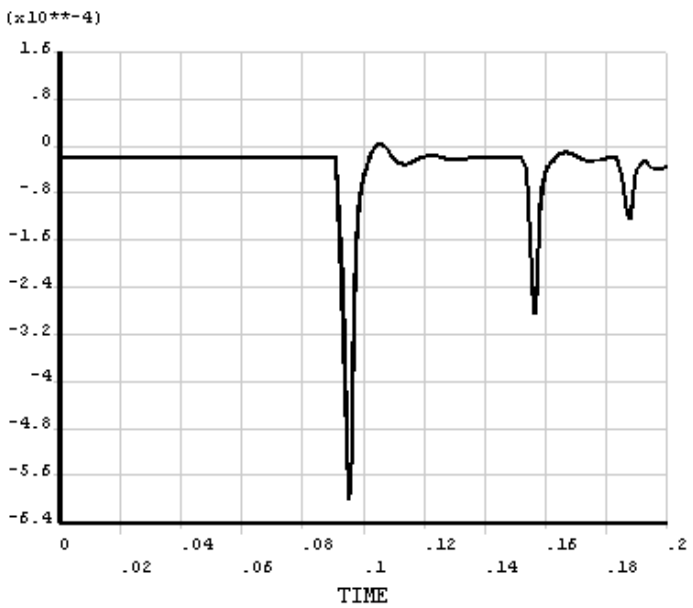

Figure 6: Displacement of Rail (HTMD, $\mathrm{k}=50 \mathrm{kN} / \mathrm{mm})$.

Fastener stiffness has a great influence on the vibration reduction performance. The lower the stiffness of the fasteners, the bigger vertical displacement the rail is. At the same time the smaller the fasteners' force is.

Tuned mass has a certain effect on the whole system. As the increase of tuned mass in TMD, the vibration reduction effect is better. Comparing HTMD with 
common track and TMD systems, both the fasteners force and displacement of rail have a greater degree of vibration attenuation.

\section{Wheel/rail response result analysis under dynamic load}

From Figures 7-10, acceleration curves show that the peak acceleration of rail and track bed of TMD is reduced when compared with common track. Track with HTMD has greater reduced amplitude than the other two tracks.

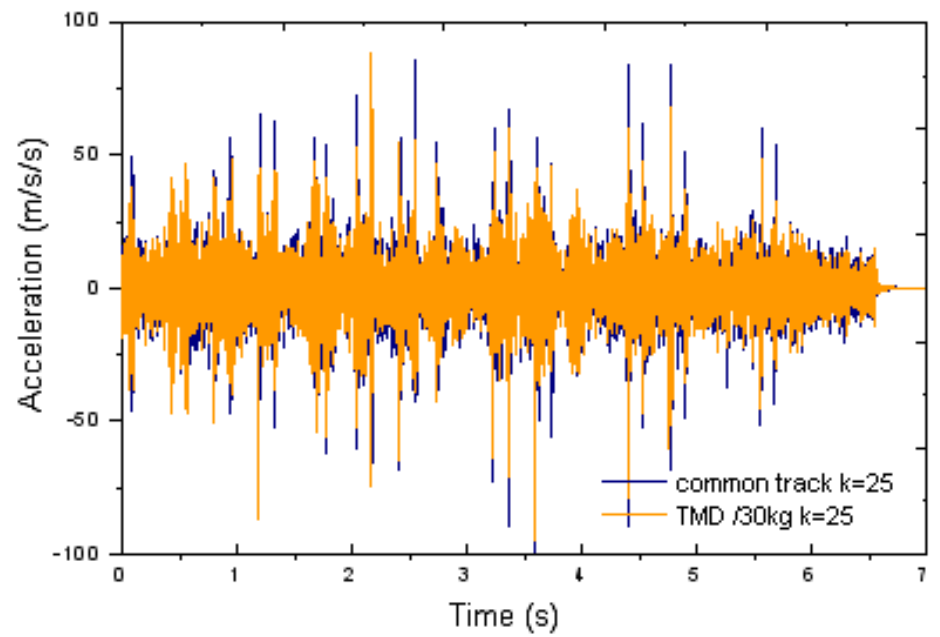

Figure 7: Rail acceleration history (common track and track with TMD).

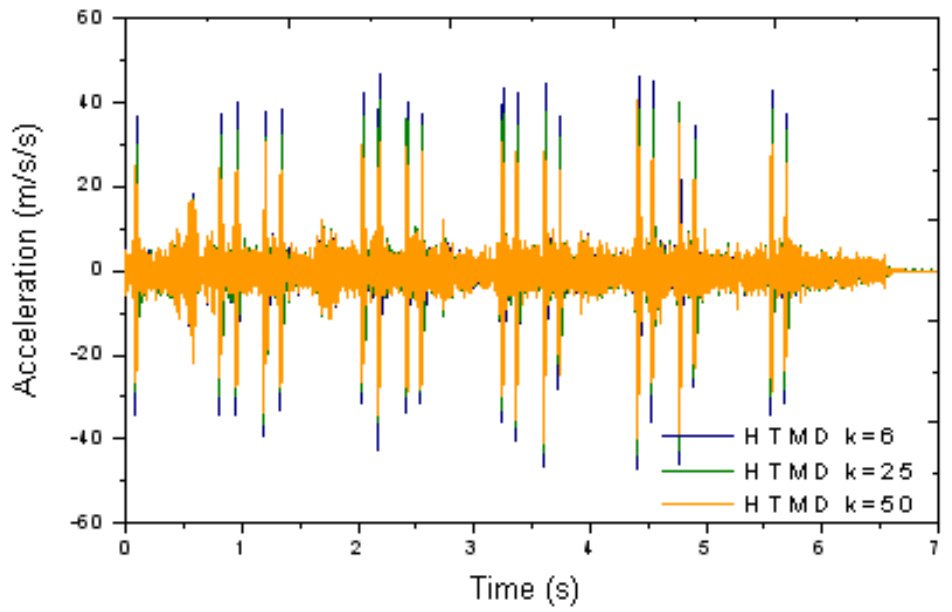

Figure 8: Rail acceleration history (HTMD). 


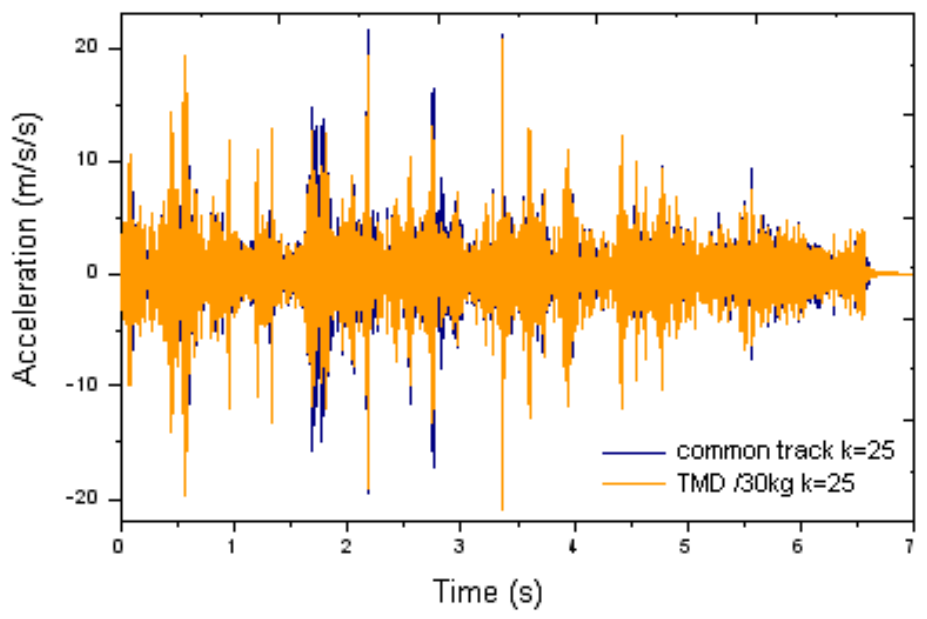

Figure 9: Track bed acceleration histories (common track and track with TMD).

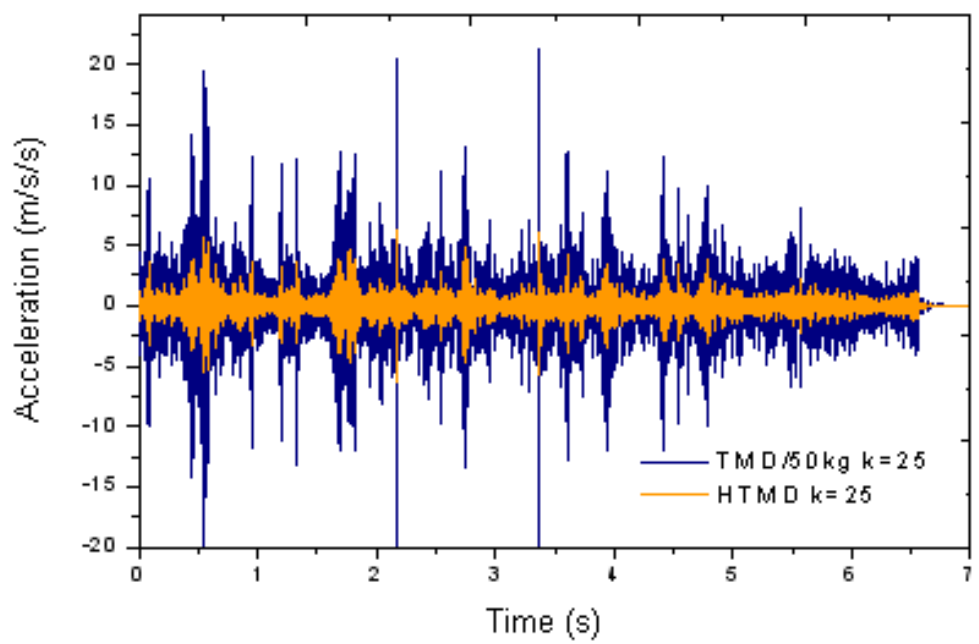

Figure 10: Track bed acceleration history (track with TMD and track with HTMD).

The analysis results indicate that when the stiffness of fasteners decreases, the track vibration level decreases. $Z$ vibration level of track bed in common track is 66-69 dB; Z vibration level of track bed in HTMD system is 55-60 dB, which shows that the HTMD system has a remarkable effect. 
Table 5: $\quad$ Vertical vibration level.

\begin{tabular}{|c|c|c|}
\hline \multirow{2}{*}{ common track } & $\begin{array}{c}\text { Fastener stiffness } \\
(\mathrm{kN} / \mathrm{mm})\end{array}$ & $\begin{array}{c}\text { Vertical } \\
\text { vibration } \\
\text { level }(\mathrm{dB})\end{array}$ \\
\cline { 2 - 3 } & 6 & 111.70 \\
\cline { 2 - 3 } & 25 & 106.38 \\
\hline \multirow{3}{*}{ HTMD } & 50 & 102.61 \\
\cline { 2 - 3 } & 6 & 91.01 \\
\cline { 2 - 3 } & 25 & 87.74 \\
\hline
\end{tabular}

\section{Conclusion}

Through modal analysis to the common track and heavy mass tuned system track structure, the relationship between stiffness of fasteners and natural frequencies has been obtained. When the common fasteners are used, the first order frequency of HTMD system is 20 to $30 \mathrm{~Hz}$. The first 6 orders are within $40 \mathrm{~Hz}$. When adopting high elastic fasteners, the first order of HTMD track is below $20 \mathrm{~Hz}$, which is close to light FST. The subway can have a large degree of vibration reduction, which is a highly efficient method to both operating lines in the reconstruction.

The wheel-set drop simulation shows the parameters have an influence on track vibration reduction. Analysis results show that lower fastener stiffness have good contribution to vibration control. Under the same impact height, the rail vertical displacement reduces by nearly half compared with common track, so as fasteners force.

The dynamic load test shows that the vibration level of track bed has $5 \mathrm{~dB}$ reduced when using different stiffnesses of fasteners. Compared with common track, the vibration level of HTMD track reduces by about $15 \mathrm{~dB}$. It can be regarded as a good vibration reduction rail structure.

\section{Acknowledgements}

This work was financially supported by the Fundamental Research Funds for the Central Universities (Tongji University), National Science and Technology Support Plan (2009BAG11B02).

\section{References}

[1] Chen, Y., \& Huang, Y., Timoshenko beam with tuned mass dampers and its design curve. Journal of Sound and Vibration, 278: pp. 873-888, 2004. 
[2] Wang, J. F., Lin, C. C. \& Chen, B. L., Response to comments on: "Vibration Suppression for High Speed Railway Bridges Using Tuned Mass Dampers". International Journal of Solids and Structures, 42: pp. 6520-6521, 2005.

[3] Kanto, Y., \& Y.G. A dynamic contact buckling analysis by the penalty finite element method. International Journal Numerical Methods Engineering, 29 (3), pp. 755-774, 1990.

[4] Ludvigh, E, Elastic Behaviors of Continuously Embedded Rail systems. Periodical Polytechnica, 46 (1), pp. 103-114, 2002.

[5] Harris, C.M., \& Piersol, A.G., Harris's Shock and vibration handbook, McGraw- Hill Companies, Inc., pp. 159-167,2008.

[6] Wang Q., Research on track impact using wheel-set drop method. Journal of the China Railway Society, 14(3), pp. 102-109, 1992. 